Letras, Lima 48 (82-83): 149-156, 1976.

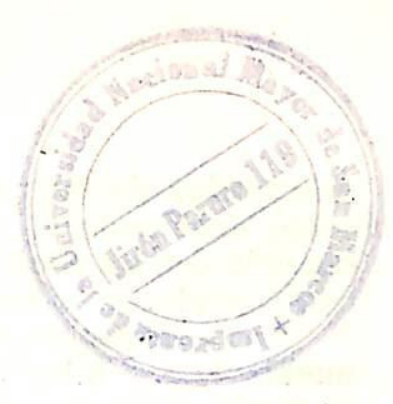

\title{
La función del mito en La región más transparente de Carlos Fuentes
}

EDMUNDO BENDEZU AIBAR

La novela se inicia con un monólogo que es un poema en prosa, que trata de sintetizar con un lenguaje poético exuberante, con metáforas audaces y deslumbrantes, el tema central de la novela: la condición del hombre mexicano actual, que busca su identidad auténtica, dentro de una dura existencia cotidiana. Esto aparece enfáticamente, como una sombria tarjeta de presentación, desde las primeras palabras: "Mi nombre es Ixca Cienfuegos. Nací y vivo en México, D.F. Esto no es grave. En México no hay tragedia: todo se vuelve afrenta. Afrenta, esta sangre que me punza como filo de maguey JAfrenta, mi parálisis desenfrenada que todas las auroras tiñe de coágulos. Y mi eterno salto mortal hacia mañana" (1).

"En México no hay tragedia: todo se vuelve afrenta" son las palabras claves que dan el tono predominante a toda la narración, de tal manera que se puede decir que toda la novela no es sino un comentario al sentido de esas terribles palabras, que conjuran la presencia purificadora del mito.

El hombre mexicano está simbolizado principalmente por Ixca Cienfuegos, personaje misterioso, que es como una reencarnación de algún dios azteca, que pronuncia las palabras claves y, a lo largo de toda la novela, es un poderoso catalizador, ante quien los otros seres de ficción relatan sus vidas y ante cuya conciencia mítica confluyen los incidentes novelescos como los hilos de una gran madeja.

Ixca Cienfuegos funciona como un eje que da coherencia y unidad a la novela. En su conciencia se reflejan los conflictos fun-

(1) Carlos Fuentes. La región más transparente. México, Fondo de Cultura Económica, 1958. Citamos por la 6a. ed.: 1968, p. 9. 
damentales de los personajes $\mathrm{y}$, en el momento climático, es él quien desenreda el nudo de los destinos de esos personajes, de acuerdo con los designios que él ha determinado y que son los que corresponden a la estructura del mito.

Las características de la existencia mexicana, al promediar el medio siglo y tal como Cienfuegos la contempla, son: la derrota, la parálisis, la incomunicación, la bravuconada, el sentimentalismo, la preocupación por la muerte, la incertidumbre del futuro, la búsqueda del placer, la vocación por la libertad, su capacidad para vivir entre un pasado ancestral y un presente desquiciado.

La derrota del hombre mexicano, en la voz exaltada de Cienfuegos, lo coloca frente al pasado como única alternativa: "joh derrota mía, mi derrota, que a nadie sabría comunicar, que me coloca de cara frente a los dioses que no me dispensaron su piedad, que me exigieron apurarla hasta el fin para saber de mí y de mis semejantes!" (p. 9). Así, frente a los dioses aztecas, Cienfuegos toma conciencia de la presencia del otro mexicano, que se encuentra ahí pero a quien echa de menos: "Aquí vivimos, en las calles se cruzan nuestros olores, de sudor y pachulí, de ladrillo nuevo y gas subterráneo, nuestras carnes ociosas y tensas, jamás nuestras miradas. Jamás nos hemos hincado juntos, tú y yo, a re cibir la misma hostia; desgarrados juntos, creados juntos, sólo morimos para nosotros, aisladods, Aquí caímos. Qué le vamos a hacer. Aguantarnos, mano A ver si algún día mis dedos tocan los tuyos" (p. 10).

Cienfuegos descubre pues, con las palabras arriba citadas, al otro mexicano, aunque tencel discureir delsrelato se mueve él con suma facilidad entre las dos identidades como quien se pone y quita máscaras, al punto de que no sabemos quién es Cienfuegos, hecho que toca el problema fundamental de hombre con una identidad dividida, que no sabe quién es y que, por eso, está buscando desesperadamente la integración de su yo dentro de una sola identidad.

Ese mexicano no es otro que el mexicano ancestral, que supervive $\mathrm{y}$ vive su propia vida, $\mathrm{y}$ que es como una parte que falta de la identidad del mexicano actual. Paradójicamente él estáahí, su presencia es constante. El es el "Duende de Anáhuac" que está y no está, que se le ve y no se le ve. Tiene también, sin embargo, sus características específicas: ama la violencia sangrienta, está cerca de la tierra, vive con la muerte, no persigue la alegría sino el sufrimiento, se ofrece al sacrificio "de hinojos, coronado de nopales" y muere violentamente todos los días. Es a este mexicano a quien Cienfuegos busca simbolizando al otro mexicano, porque tiene la identidad rota, es decir, el "cuerpo fracturado, de trozos centrífugos, gimientes de enajenación" (p. 9). Y cuando lo encuentra exclama apasionadamente: " "No te rajes, manito! Saca tus pencas, afila tus cuchillos, niégate, no hables, no compadezcas, 
no mires. Deja que toda tu nostalgia emigre, todos tus cabos sueltos: comienza, todos los días en el parto. Y recobra la llama en el momento del rasgueo contenido, imperceptible, en el momento del organillo callejero, cuando parecería que todas tus memorias se hicieran más claras, se ciñeran. Recóbrala solo. Tus héroes no regresarán a ayudarte. Has venido a dar conmigo, sin saberlo, a esta meseta de joyas fúnebres" (p. 10).

El encuentro de la faz europea con la faz indígena del mexicano, culturalmente hablando, necesita para la solución del conflicto implícito en ellas, dentro de la estructuración de La región más transparente, de una recreación verbal del mito azteca; porque el mito, según el estudio morfológico de André Jolles, es una forma que surge de la actividad mental dirigida hacia el saber, pero no se trata de un saber al que se dirige el conocimiento racional ni tampoco el saber científico universalmente válido que condiciona a la experiencia; se trata, más bien, de un saber absoluto, incondicionado, que se origina en una pregunta y en su respuesta, que puede objetivarse en una estructura verbal y que prevalece gracias a esa estructura lingüística que es portadora de una verdad. Ahora bien, la pregunta con su respuesta están en la actividad mental orientada hacia el saber mítico y pueden actualizarse u objetivarse en diferentes formas lingüísticas, ya sea en lo que Jolles llama formas simples de la literatura oral o en las formas más complejas de la literatura escrita (2).

No queremos decir que toda la novela de Fuentes sea un mito, sino que en ella el mito cumple una función estructurante, planteando preguntas y proponiendo respuestas, lo que supone una solución, aunque tal vez precaria, del conficto de identidades del ser mexicano. La preseridiar Getualizadal se veen los monólogos interiores y en algunas instancias de la trama, sobre todo en el monólogo que introduce la novela, que es más bien un poema en prosa, y en el que concluye la novela, que es verdaderamente un monólogo interior que pretente encerrar en algunas páginas toda la historia mexicana y toda la historia de La región más transparente.

La interrogación que instaura el mito con el monólogo inicial de Cienfuegos se dirige al ser del hombre mexicano, y la respuesta nos revela la fundamental dicotomía de ese ser con la presencia, lado a lado, de dos identidades; una de las cuales, la más antigua, se manifiesta a través del acto simbólico del sacrificio humano, que entre los aztecas era un acto místico, el ritual religioso de la sangre, que hacía propicia la voluntad de sus dioses (3).

(2) André Jolles. Einfanche Formen. Tübingen, Max Niemeyer Verlag, 1930. Traducción francesa: Formes simples. Paris, Editions du Seuil, 1972. Citamos por la traducción española: Las formas simples. Santiago de Chile, Editorial Universitaria, 1972, p. 99.

(3) M. Ciges Aparicio y F. Peyro Carrió. Dioses, mitos y héroes de la Humanidad. México, Ediciones Pavlov, 1934. Ver: p. 508. 
En el monólogo final de la novela, que ocurre en la conciencia de un narrador omnisciente, aparece nítidamente revelada la verdad del mito en una forma actualizada que, en la técnica novelís tica, utiliza "el fluir de la conciencia" para lograr una plenitud artística.

El narrador dice: "el cuchillo de jade es largo, y la noche te lo entregó con una boca sangrante y desdentada, ¿cómo puedes rechazar las súplicas de la noche, que son los ruegos de tu imagen? largo es el cuchillo, cercanos los corazones, pronto el sacrificio que otorgas sin caridad, sin furia, veloz y negro, porque te lo pides a ti mismo, porque tú quisieras ser ese pecho herido, ese corazón levantado -mátalo en la primavera de resurrecciones, la primavera eterna que no te permite contar las canas, las otras caricias, las señales, los trónsitos; mata a ése, igual a sí mismo, que eres tú, mátalo antes de que pueda hablar porque el día que oigas su voz no lo podrás resistir, sentirás odio y vergüenza y querrás vivir para él, que no eres tú, que no tienes nombre: mátalo y creerás en él, má́talo y tendrás tu héroe: acerca, acerca el fuego a sus pies para que la carne ascienda hasta el polvo y tus restos vuelen sobre el valle, exactos sobre el meridiano de los nombres, nombres densos y graves, nombres que se pueden amasar en oro y sangre, nombres redondos y filosos como la luz del pico de la estrella, nombres embalsamados de pluma, nombres que gotean los poros de tu única máscara, la máscara de tu anonimato: la piel del rostro sobre la piel del rostro, mil rostros una máscara Acamapichtli, Cortés, Sor Juana, Itzcóatl, Juórez, Tezozómoc, Gante, Ilhuicamina, Madero, Felipe Angeles, Moroheses,oCárdenase Calles, Obregón,..." (p. 445). Y así, continúa una larga enumeración de los nombres que han hecho la historia mexicana.

La dicotomía esencial del ser mexicano se resuelve así en un acto simbólico de sangre, que seguramente ha de purificar y restituir la unidad fundamental del ser, desde la perspectiva del mito, del ser que se nutre en aquello que la invocación reclama: "que el gran lago de sangre de México no se seque, no se seque jamás, único río eterno, única humedad floreciente bajo. el sol furioso" (p. 453).

Los dioses aztecas: Huitzilopochtli, "el colibrí del sur" que condujo a los aztecas hasta Tenochtitlón, el terrible Tezcatlipoca, "espejo humeante" y dios sol y Tlaloc, "la pulpa de la tierra" y dios de las montañas, de la lluvia y de los manantiales; todos ellos exigían la inmolación de las víctimas y todos nos parecen retornar secretamente en las formas actualizadas del mito (4).

Carlos Fuentes tiene plena conciencia de ello cuando afirma en broma y en serio: "La verdadera venganza de Moctezuma no

(4) New Larousse Encyclopedia of Mythology. London, Paul Hamlin, 1968. Ver: pp. 436,437 y 439. 
es la disentería: es el sentido permanente del sacrificio para mantener el orden del cosmos. Esa ha sido la victoria final del mundo indígena en México" (5).

Desde otra perspectiva, el retorno de los dioses mexicanos puede ser interpretado también como un intento, de parte del novelista, de rebasar la degradación del mundo en que sus personajes viven. Carlos Fuentes, desde su primer libro de cuentos Los días enmascarados (1954), no sólo ha sentido la presencia de los mitos mexicanos sino que ha visto su necesidad (6).

En un ensayo periodístico, Fuentes propone: "Bastan estas notas para comprender hasta qué grado la cultura indígena posee muchas claves para disolver las neurosis modernas. ¿Vale la pena destruir esta aportación para meter a los indios en el embudo de Pepsicóatl, en la sociedad hecha de sucedáneos, de ersatz de la producción norteamericana?" (7)

Si en La región más transparente Fuentes trata de recobrar literariamente el pasado mítico mexicano, no es esa la única preocupación del novelista. Existe algo más que puede explicar la presencia del mito y ello nos parece bastante claro cuando Fuentes afirma: "Entonces yo creo que La región más transparente es una novela que reflejaba mucho, intencionalmente por lo demás - sin ser mi tesis ni mucho menos-, la preocupación de ese momento por fijar, por resumir, por destilar 'lo mexicano'; reflejaba esa preocupación excesiva y mítica por la nacionalidad, por la tierra, por el pasado de México. Al mismo tiempo pretendía ser una novela crítica de la Revolución, en un momento en que se podía tener perspectiva sobre lo que había sido la Revolución Mexicana, perspectiva que no pydieron tener los novelistas documentales que escribían cabalgando con Panch tiila" (8).

Este es el tema central de la novela que explica la presencia del mito o que hace más coherente su necesidad. Entre los dos monólogos que abren y cierran la novela y hacen posible con su juego de pregunta y respuesta, el mito se abre un espacio muy grande, que es el espacio del discurso novelesco, con multitud de personajes e incidentes, con varias secuencias narrativas en diferentes planos temporales, con diálogos ágiles, con especulaciones graves y con veloces flashbacks. En ese vasto espacio narrativo, que constituye el cuerpo de la novela, se agita la conciencia crítica del novelista. Y lo que se cuenta y presenta, con una técnica

(5) Emir Rodríguez Monegal. El arte de narrar. Caracas, Monte Avila Editores, 1968 , p. 118.

(6) Luis Harss. Los nuestros. Buenos Aires, Editorial Sudamericana, 1966, pp. 348-350.

(7) Carlos Fuentes. Tiempo mexicano. México, Editorial Joaquin Mortiz, 1972, p. 37.

(8) Luis Harss. Op. cit., p. 359. 
retrospectiva y en un momento preciso de la historia, 41 años después del estallido de ese gran cataclismo social que fue la Revolución Mexicana, es la desintegración de la sociedad que nació de ese parto histórico; pero hay que advertir que no se trata de una desintegración política institucional sino más bien de una estructura ética. Lo que teóricamente hace posible la existencia de la novela como género son las preocupaciones y conflictos éticos según Lukács, quien afirma que en la novela "es la ética la intención en la forma de cada detalle perceptible, es por eso, en cuanto a su contenido más concreto, una eficaz construcción de la obra mis$\mathrm{ma}^{\prime \prime}$ (9).

Hory en Carlos Fuentes una evidente intención de juzgar en términos éticos los resultados de la Revolución Mexicana; y, para ello, reclama para sí una mejor perspectiva temporal "de la misma manera que Chateaubriand no escribió la novela de la Revolución Francesa, sino Balzac y Stendhal, cuarenta o cincuenta años después" (10). Esta intención le da a La región más transparente un tono apasionado a veces, cruel otras veces e irónico muchas veces. Todos los personajes están teñidos, como en un crepúsculo, por los colores que el narrador intencionalmente escoge. La misma técnica de presentación contrastiva de escenas de la gran ciudad está determinada por esa intención, aun cuando ciertos personajes no juegan un papel importante en las principales secuencias de acontecimientos narrados, por ejemplo la prostituta Gladys García, el obrero Gabriel con sus amigos y los que aparecen en las fiestas de la burguesía.

Es cierto que Fuentes utiliza la ironía y el humor para rebasar la degradación del mundo de la era postrevolucionaria, tal como aparece en la conciencial de sus persofiajes." Esa ironía y ese humor deben entenderse de acuerdo con la interpretación que Lucien Goldmann hace del concepto de ironía y humor como formas de rebasamiento en las teorías de Lukács y Girard (11). Pero tal vez más importante que la ironía o el humor, en nuestra opinión, es la recreación verbal y literararia del mito que, desde la perspectiva del novelista y con la ideología ético-religiosa de la cultura occidental a la que pertenece no obstante su mexicanidad; la recreación del mito, en su forma de violencia sacrificial, como mecanismo de expiación para rebasar la degradación del mundo representado. Claro que podía argüirse diciendo que con el mito se trata más bien de invocar, a través de la inmolación, a los dioses aztecas para la restitución en el mundo de un orden quebrado; pero esto no

(9) Georg Lukács. Die Theorie des Romans. Berlin, Paul Cassirer, 1920. Neuauflage, Neuwied und Berlin, 1971, p. 62.

(10) Luis Harss. Op. cit. p. 359.

(11) Lucien Goldmann. Pour une sociologie du roman. Paris, GaIlimard, 1964, p. 30. 
invalida la existencia de un sentimiento expiatorio, por lo menos en niveles subconcientes, de un origen no indígena.

El mundo mexicano del medio siglo representado en la novela ha sufrido una total quiebra de valores, como consecuencia de que la Revolución ha establecido las formas económicas y sociales del capitalismo, apuntaladas por la penetración imperialista norteamericana. Después de 41 años de la revolución, de la que se esperabc la justicia y la liberación del hombre mexicano, en la visión de Car.los Fuentes, ese hombre ha sido hundido en la miseria, en la violencia y en la inautenticidad de una identidad dividida y alienada de sus raíces. Es todo esto que el novelista nos muestra como en un gigantesco mural mexicano. Los hijos de la Revolución entregados a pequeñas orgías en los parties de la burguesía; la fascinación por el poder financiero en Federico Robles, que hace que traicione su mismo origen campesino y revolucionario y se convierta en un desalmado; la prostitución de la poesía en Rodrigo Pola, hijo de un revolucionario inmolado en las primeras horas, que le permite ser aceptado en los círculos de la burguesía a los que siempre había soñado arribar; la prostitución por hambre de Gladys García y la otra por arribismo de Norma Larragoiti; Pimpinela Ovando, supérstite de una aristocrácia que no quiere desaparecer, sobrevive con la adulación y el brillo de unas apariencias que la nueva burguesía busca afanosamente; los hijos pobres de la revolución se mueven en la miseria y en la sangre de su violencia ancestral; los intelectuales como Manuel Zamacona que sólo teorizan sobre la liquidación de ese orden de cosas; las madres de todos sufren en silencib; e Ixca Cienfuegos que busca con la anciana Teódula Moctezuma restablecer el imperio de los dioses mexicanos a través de secretos fitualesi f lavactualización del cuchillo de obsidiana para el sacrificio humano que, con el retorno del mito azteca, ha de restablecer el perdido equilibrio del mundo. Cienfuegos, máscara o catalizador del narrador omnisciente, conciencia crítica de todos los personajes, testigos y partero de recuerdos que fluyen como ríos, interviene pocas veces como personaje de la anécdota y cuando lo hace oye el reclamo de los dioses en el fallido intento de asesinato de Norma Larragoiti, quien más tarde perece en un incendio cruelmente previsto por el mito, ella era la víctima más hermosa y soberbia. Cienfuegos también, con una hábil jugada destruye los pies de barro del banquero Robles, cuya caída es, paradójicamente, salvación de su alma mexicana. Los otros, sin razón aparente, se ahogan en la sangre: Gabriel, atravesado por el cuchillo de un perseguidor gratuito; Zamacona perece en la boca de la pistola de un desconocido a quien lo miró de "esa manera" y el mismo Cienfuegos se esfuma en la niebla de una calle de la región más transparente del aire.

Hay pues demasiadas muertes absurdas y Carlos Fuentes trata de explicarlas en términos de la realidad mexicana en una en- 
trevista con Rodríguez Monegal: "México -dice Fuentes- es un país del instante. El mañana es totalmente improbable, peligroso: te pueden matar en una cantina, a la vuelta de una esquina, porque miraste feo, porque comiste un taco" (12). Rodríguez Monegal comenta no sin malicia: "uno de los episodios que me pareció más fabricado, es decir, más puesto ahí por el autor con una intención deliberada, y hasta si se quiere, perversa, fue el asesinato casual de Zamacona en una cantina". Y concluye con una explicación fócil: "Después de vivir cuatro meses seguidos en México, comprendí que tú habías sido estrictamente realista en tu ficción. Allí sentí una tensión que hace posible las cosas más absurdas, esos sacrificios bruscos, sin sentido aparente" (13).

Pero, para nosotros, los sacrificios aparentemente absurdos en la novela tienen sentido cuando se piensa que ellos forman parte del mito y que éste subyace en la base de la estructura de la novela y muchas veces aflora en los monólogos, en algunos incidentes del argumento $\mathrm{y}$, sobre todo, en el sentido total del mundo novelesco creado por Fuentes. No está demás volver a citar las palabras del novelista: "salir de la historiografía, de la redacción de la historia, para entrar en la dialéctica, que es hacer la historia y hacerla con los mitos que nos dan los hilos de Ariadna de todo ese pasado utópico y épico para convertirlo en otra cosa. A través del mito re-actuamos el pasado, lo reducimos a proporción humana" (14). Y más adelante afirma algo que es muy importante en la concepción del mito: "Lo importante de los mitos vivos, no de lo mistificado, sino de lo mitificado, es que en realidad nunca se cierran. Parece que se han cerrado y no es cierto" (15).

Terminamos afirmando que un novelista contemporáneo como Fuentes es un recreador ldecmilos Goléstá, Sen nuestra opinión, es una de las vías de apertura del callejón sin salida en el que se había detenido la novela europea realista. Esto es un aporte de singular mérito para la novela hispanoamericana de nuestro tiempo, que la coloca, con pleno derecho, en una perspectiva universal.

(12) Emir Rodríguez Monegal. Op. cit., p. 118.

(13) Ibíd., p. 118.

(14) Ibíd., p. 133.

(15) Ibíd., p. 133. 